\title{
LA ALFARERÍA IMPERIAL INKA: UNA COMPARACIÓN ENTRE LA CERÁMICA ESTATAL DEL ÁREA DE CUZCO Y LA CERÁMICA DE LAS PROVINCIAS
}

\author{
IMPERIAL INKA POTTERY: A COMPARISON OF STATE CERAMICS \\ FROM THE CUZCO HEARTLAND AND THE PROVINCES
}

\author{
Tamara L. Bray*
}

\begin{abstract}
Se presentan los resultados preliminares obtenidos mediante el estudio en curso de vasijas incaicas depositadas en colecciones de museos de diferentes partes del mundo. A partir de este análisis se plantea que el complejo cerámico estatal del imperio Inka no es tan homogéneo, ni estuvo tan uniformemente distribuido a través del Tawantinsuyu, como tradicionalmente se ha pensado. En este artículo se comparan las frecuencias, los tamaños y las variantes estilísticas de la cerámica imperial recuperada en el centro estatal del Tawantinsuyu de Cuzco y su vecindad con materiales procedentes de las provincias. El significado de las similitudes y diferencias registradas entre el complejo cerámico del centro versus el de las provincias será discutido en el marco del contexto de la política del estado imperial.
\end{abstract}

Palabras claves: Tawantinsuyu, Inka, alfarería incaica, iconografía, colecciones museológicas.

An on-going study of complete Inka vessels found in museum collections suggests that the imperial assemblage is not as homogeneous or as evenly distributed throughout the empire as commonly thought. In this paper I compare frequencies, sizes, and stylistic variants of imperial Inka pottery from the Cuzco heartland region to materials found in the provincial districts of the empire. The significance of the differences and similarities noted between core and provincial assemblages are explored within the context of imperial state politics.

Key words: Tawantinsuyu, Inka pottery, iconography, museum collections.

El complejo cerámico asociado con el estado imperial de los Inkas ha sido ya por mucho tiempo reconocido por su naturaleza uniforme y repetitiva. En efecto, John Rowe una vez sugirió que fue tan constante que se podría reconstruir con confianza una vasija entera a partir de un solo fragmento (1944:8). A menudo, la adhesión estricta a los cánones formales y estilísticos ha sido interpretada casualmente como evidencia de producción en gran escala, en unos casos (Jones 1964:8; Rowe 1944:48), y como ejemplificación del arte corporativo, en otros (e.g., Moseley 1992:73). Aunque tales opiniones son frecuentes, han sido muy pocos los estudios sistemáticos de la alfarería Inka que nos permitan evaluar críticamente éstas y otras suposiciones comúnmente aceptadas acerca de la importancia y el significado del complejo imperial Inka.

Para comenzar a abordar algunas de estas cuestiones, inicié hace varios años un proyecto de fotodocumentación de materiales Inkas albergados en museos, con la intención de desarrollar una base de datos sobre la cerámica imperial que permitiera analizarla sistemática y comparativamente. Hasta la fecha, he completado la documentación de colecciones de cerámica Inka en Perú, tanto en el Museo Nacional de Arqueología e Historia en Lima como en el Museo Inka y del INC en Cuzco entre otros; en Ecuador, en los Museos del Banco Central en Quito y Cuenca, en el Museo de Jijón y Caamaño en Quito, así como en otras instituciones y colecciones privadas; en los Estados Unidos, en el Museo Americano de Historia Natural, en el Museo Field en Chicago (que posee una gran colección del Cuzco comprada a un Sr. Montez en el año 1893), y en los Museos del Smithsonian en Washington, D.C.; y, finalmente, en el Museo Británico en Londres. Como parte del proceso de documentación, obtuve numerosos datos, incluyendo información sobre las dimensiones de las vasijas, el tratamiento decorativo, la fabricación, el contexto del hallazgo y la procedencia. Además de las colecciones de los museos, la base de datos contiene información publicada sobre vasijas incaicas recuperadas arqueológicamente.

* Wayne State University, Detroit, Michigan 48202. 
Desde el principio, mi intención ha sido obtener un registro completo de estas colecciones más que enfatizar únicamente piezas selectas o representativas. Hasta el momento, la base de datos comprende más de 2.000 imágenes y registros de vasijas incaicas que proceden de todo el ancho y largo del imperio. Si bien se reconoce que las colecciones de museos son inherentemente sesgadas y parciales, también es cierto que en una muestra suficientemente grande, los patrones significativos son perceptibles. Por otro lado, la oportunidad de trabajar con vasijas enteras es una ventaja raramente proporcionada a los arqueólogos de campo, permitiendo revelar varias correlaciones significativas. Lo que presento aquí son los resultados preliminares de un análisis comparativo de la distribución de la alfarería incaica entre el corazón imperial (definido como el área de Cuzco y el valle de Urubamba) y las provincias, con respecto a los tipos morfológicos, los tamaños de las vasijas y los tratamientos decorativos.

Inicio esta discusión señalando en primer término que, en mi análisis de la vajilla imperial, observo una íntima vinculación entre el complejo cerámico, los alimentos y la política. En lugar de mirar simplemente a la cerámica Inka como un marcador o indicador del estado, la concibo como un punto importante de articulación entre la producción, el consumo, la identidad y los procesos imperiales. Dentro de este marco, sugiero que el significado y la importancia de la distintiva alfarería policroma asociada con el Tawantinsuyu está fuertemente involucrada en las prácticas y procesos políticos del imperialismo Inka. En este sentido, es lógico asumir que las exigencias políticas del estado habrían sido diferentes en el centro imperial en comparación con los distritos provinciales y de la frontera. También es posible atribuir una dimensión temporal a la geografía del Tawantinsuyu, ya que los distintos sectores del imperio fueron sojuzgados al control del estado en momentos distintos de la historia. De acuerdo con lo expresado, podría plantearse como hipótesis que los patrones de distribución de la alfarería incaica variarán de manera sistemática, pudiendo ofrecer información sobre las estrategias políticas del estado.

El complejo cerámico de los Inka comprende un número limitado de formas distintivas y sumamente estandarizadas. En este estudio, utilizo el esquema de clasificación desarrollado por Albert
Meyers (1975) para discutir este conjunto. Las categorías morfológicas que él ideó se basaron en una revisión sistemática de la colección cerámica de Saqsaywaman y fueron diseñadas para facilitar la comparación con la alfarería Inka de las provincias. En el sistema de Meyers, el complejo estatal se divide en siete clases formales: (a) cántaros alargados con cuellos altos; (b) vasijas de cuello estrecho con bases planas; (c) vasijas de cuello ancho; (d) ollas de boca ancha; (e) ollas con o sin pie; (f) platos y escudillas y (g) vasos. En suma, hay 14 tipos de vasijas específicas (Figura 1).

El histograma de la Figura 2 indica la proporción relativa de los diferentes tipos de vasijas que comprenden la muestra de todo el imperio. Este gráfico indica que la Forma 1 de Meyers, el aríbalo, representa casi la mitad del número total de vasijas Inkas en la muestra. El plato de poca profundidad (Forma 13), el pequeño recipiente con fondo plano (Forma 5) y la olla pedestal (Forma 10), respectivamente, son las siguientes formas más comunes. En total, estos cuatro tipos de vasijas representan el 77 por ciento de las vasijas Inkas incluidas en la muestra. Cuando se compara la distribución de vasijas Inkas del corazón imperial con la colección correspondiente a las provincias, se notan algunas diferencias interesantes (Figura 3).

Puede observarse que todos los tipos de vasijas conocidos en el corazón del imperio están también presentes en los distritos provinciales, pero son distintas las frecuencias de los diferentes tipos en las dos zonas. Estas diferencias son estadísticamente significativas a un nivel de confianza de 0,99 . El aríbalo, por ejemplo, comprende casi la mitad del número total de las vasijas incaicas identificables en los distritos provinciales. Esto es bastante elevado en términos absolutos y en comparación con la región central del imperio, donde los aríbalos constituyen aproximadamente el 40 por ciento de la colección total. Además del aríbalo, las únicas vasijas que ocurren con cualquier grado de frecuencia en las provincias son los platos de poca profundidad (Forma 13) y la olla pedestal (Forma 10). Estas tres formas parecen constituir el conjunto mínimo para cualquier individuo o grupo afiliado al estado Inka viviendo en las regiones interiores. La diferencia más grande entre el corazón y las provincias parece estar en las proporciones relativas de las ollas pedestales. 


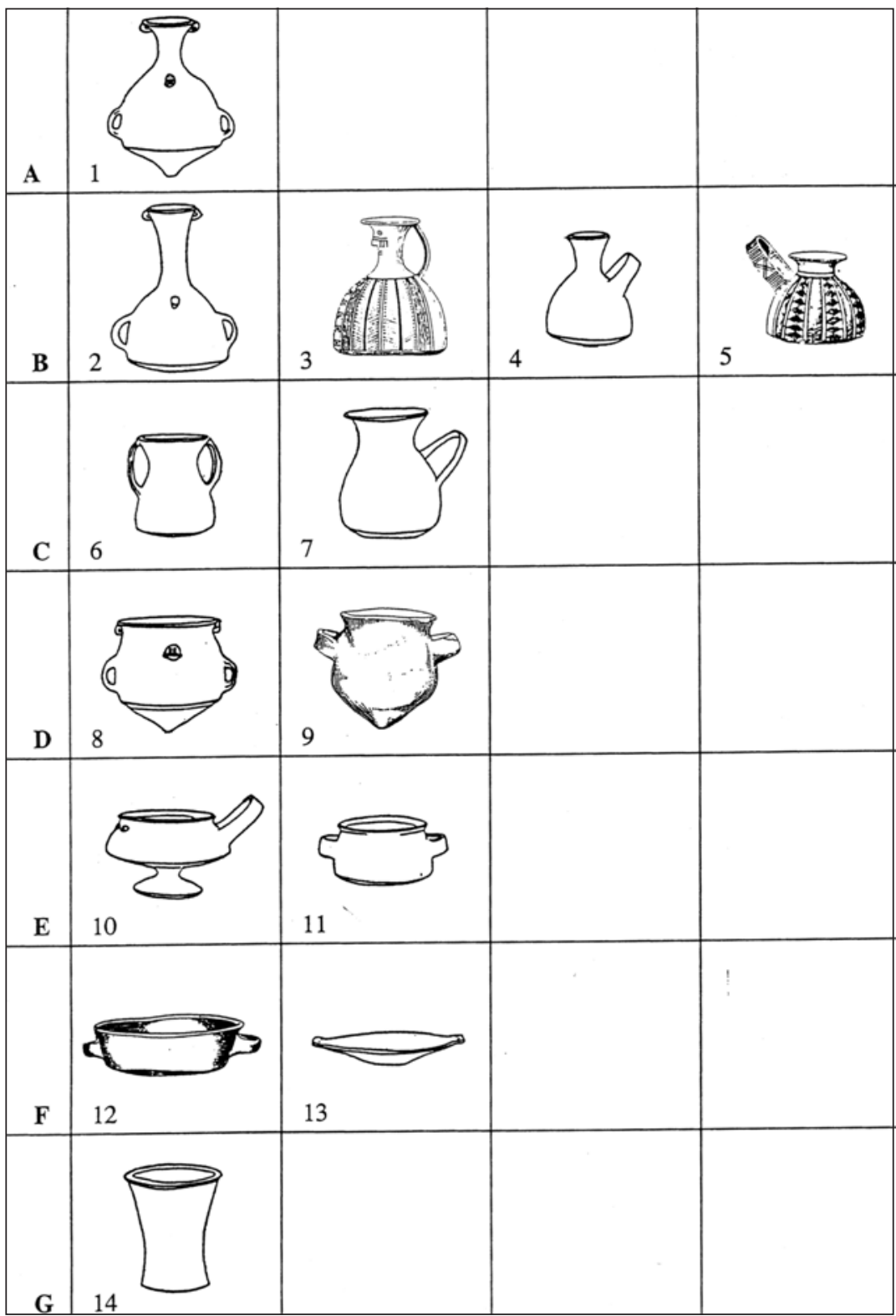

Figura 1. Clasificación de vasijas incaicas usada en el estudio (siguiendo a Meyers 1975). Classification of Inka vessels used in the study (after Meyers 1975).

Las características diagnósticas de la Forma 10, la olla con pie, incluyen una base pedestal abocinada, un asa ancha oblicuamente conectada al hombro de la vasija y un tipo de decoración plástica sencilla ubicada en el cuerpo de la vasija, en el lado opuesto del asa (consiste típicamente en un par de protuberancias pequeñas). Esta vasija también a menudo posee una tapa con asa única y ex- hibe frecuentemente hollín en su superficie exterior. Su morfología, las señales de desgaste de uso y la ausencia de decoración pintada sugieren que probablemente sirvió como vasija de cocina, quizás diseñada para el transporte. El tamaño promedio de estas ollas (12 cm de alto) indica que fueron adecuadas para la preparación de porciones más pequeñas, quizás individuales (Bray 2003a y b). 


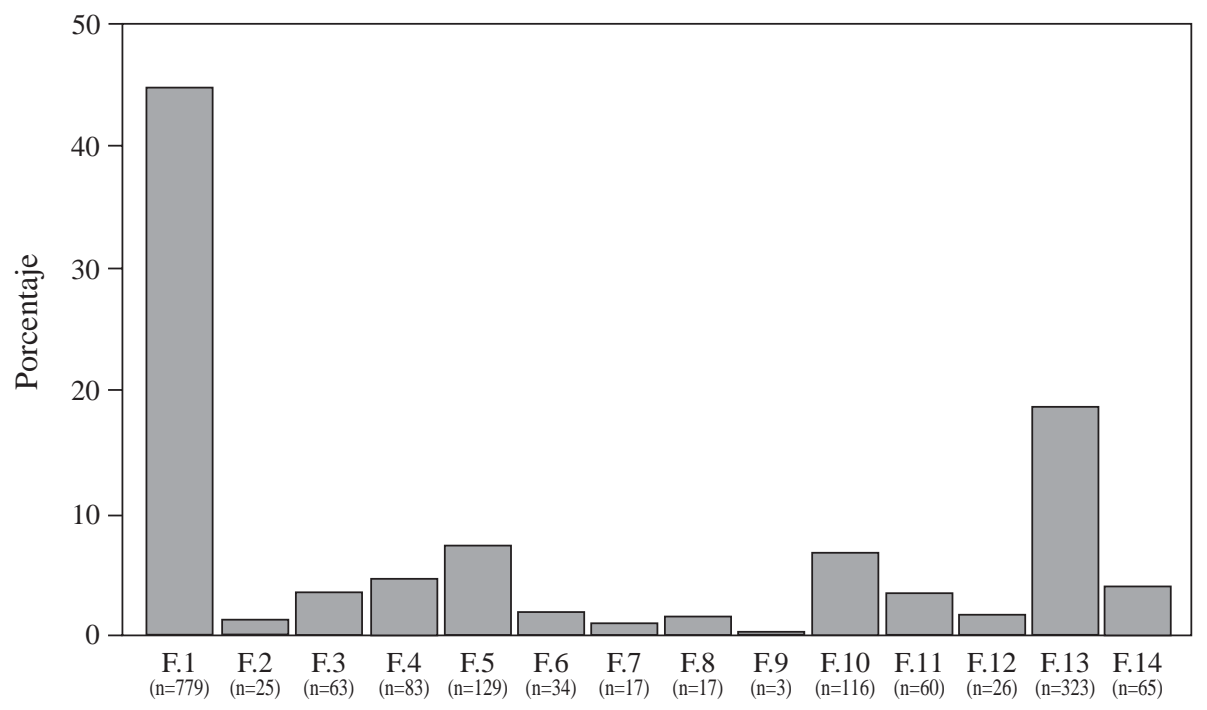

Tipo Vasija

Figura 2. Distribución de las categorías de vasijas incaicas comprendiendo el muestreo de todo el imperio $(\mathrm{n}=1.752)$.

Distribution of the categories of Inka vessels comprising the empire-wide assemblage $(n=1.752)$.

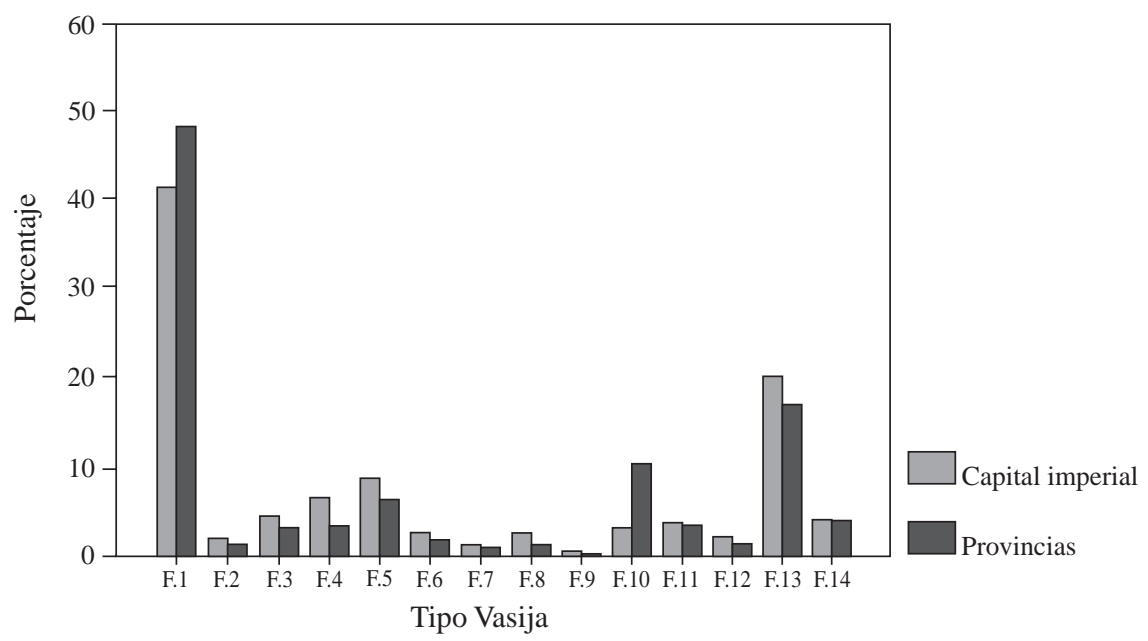

Figura 3. Comparación de la distribución de las vasijas incaicas de la capital imperial y las de las provincias $(\mathrm{n}=1.752)$.

Comparison of the distribution of Inka vessels in the imperial heartland versus the provinces $(n=1.752)$.

Con respecto a la distribución de esta forma de vasija Inka, planteo dos aspectos. En primer lugar, el número de ollas pedestales encontradas en las provincias es apreciablemente más alto que el número de tales vasijas recuperadas del corazón imperial. Las ollas pedestales comprenden 3 por ciento de la colección general del corazón imperial, contra 10 por ciento de la colección compuesta provincial. Otra observación interesante es que las ollas del tipo de las provincias son apreciablemente más grandes $(n=85 ; p>0,95)$ (Figura 4). Estos datos sugieren que la olla con pie podría re- 
presentar algo así como una "olla para la cocina de campo", o una vasija explícitamente asociada con el viaje o estando fuera de la capital. Que el estado haya autorizado la producción de una forma tan distintiva y estandarizada para una tarea típicamente vista tan mundana como la cocina, remite a la interpenetración profunda del consumo e identidad durante el Horizonte tardío en los Andes, así como a la importancia de demostrar esta identidad en las actividades diarias más básicas.

Ahora me referiré nuevamente al aríbalo, la forma más común del complejo cerámico Inka. Varios investigadores han sugerido, en base a las características morfológicas, a los contextos arqueológicos de hallazgo y a los datos etnohistóri$\cos$, que esta vasija se asocia con el almacenamiento, el transporte y para servir chicha, la ubicua y socialmente indispensable cerveza de maíz de los Andes (Bray 2003a; Morris y Thompson 1985). Se considera generalmente que los Inkas, siguiendo las normas andinas antiguas, asumieron la responsabilidad de proporcionar alimento y bebida para los trabajadores "corvée" del estado (cf. Morris y Thompson 1985; Murra 1980; Rowe 1982).
El número desproporcionado de aríbalos encontrados en las provincias en comparación con otras formas, quizás podría indicar que las prestaciones estatales de chicha eran de una importancia más grande en las regiones remotas que en el centro del imperio.

De los 312 aríbalos que podrían ser asignados a un tipo de sitio específico en base a la información de su procedencia, podemos ver que la distribución general es más o menos uniforme aunque con una excepción (Figura 5). En los sitios clasificados como fincas reales, que en esta muestra incluye sólo Ollantaytambo y Machu Picchu, hay apreciablemente menos aríbalos que lo esperado. Esto podría ser interpretado como evidencia de que en los banquetes y prestaciones públicas los aríbalos fueron menos necesarios entre los miembros presumiblemente relacionados con el cortejo real que frecuentaron estas lujosas haciendas de campo.

Unas pocas observaciones interesantes pueden también hacerse sobre las diferencias en los patrones del diseño identificadas en los aríbalos de las provincias en relación con los del centro

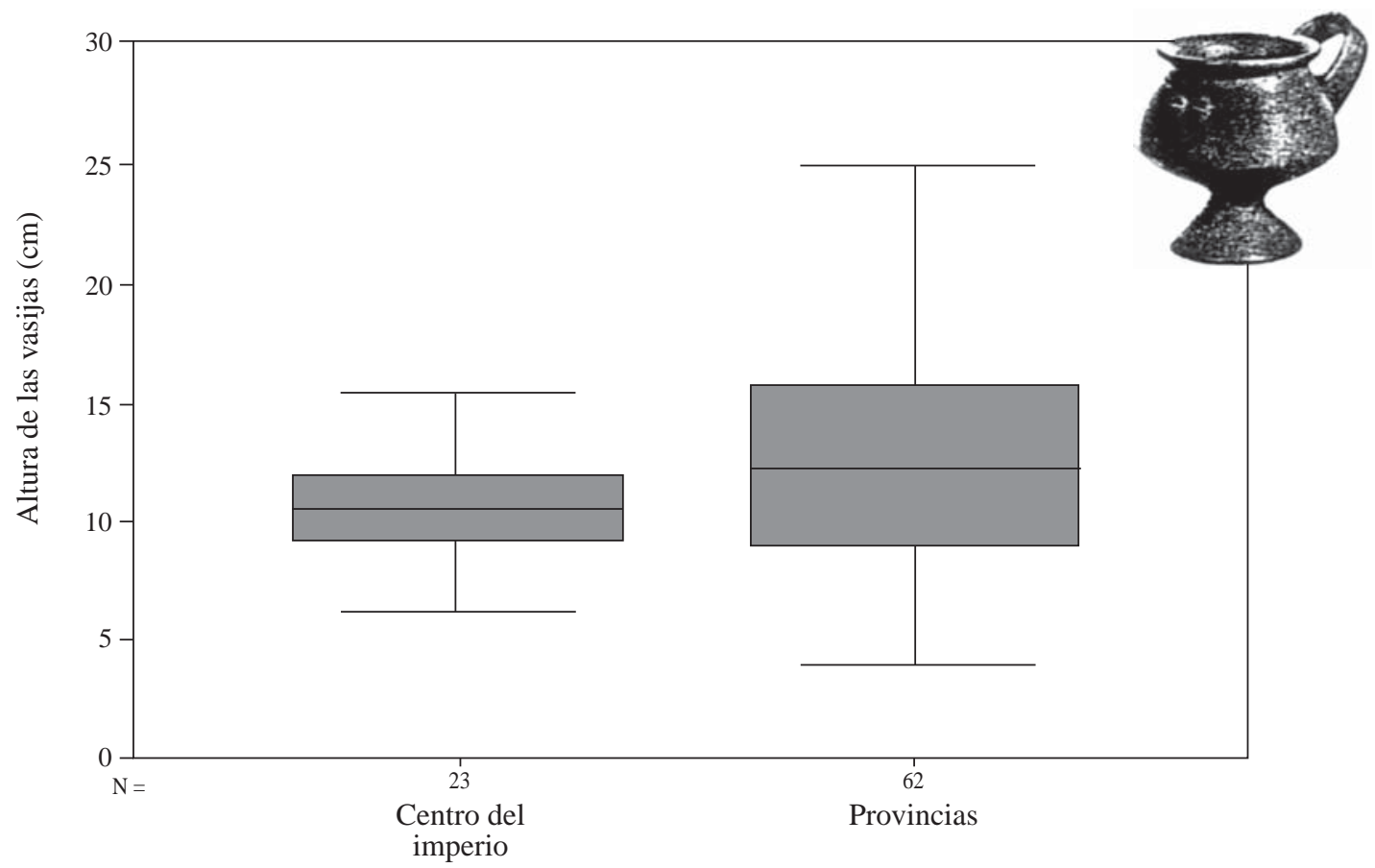

Figura 4. Comparación de la altura de las ollas con base pedestal (Forma 10) entre el centro y las provincias. Comparison of the height of pedestal-based pots from the heartland versus the provinces. 


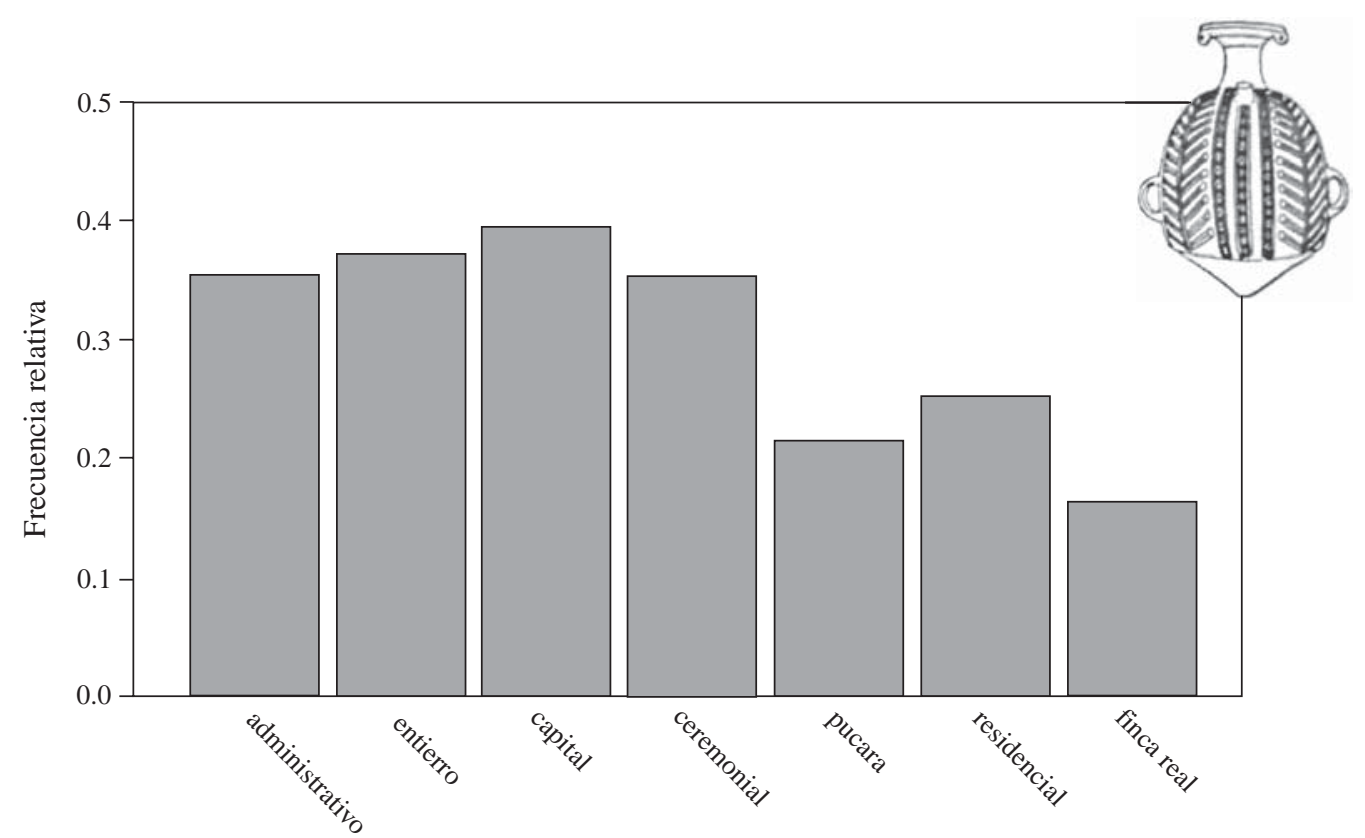

Tipo de sitio

Figura 5. Distribución de los aríbalos (Forma 1) por tipo de sitio.

Distribution of aríbalos (Form 1) by site type.

del Tawantinsuyu. En la Figura 6 se observa en primer lugar que los aríbalos simples o sin decoración son mucho más numerosos en las provincias que en la región nuclear del imperio. En segundo lugar, que en el número total de aríbalos decorados $(\mathrm{n}=517)$, tres patrones de diseño comprenden el 65 por ciento de la variación total. Los tres patrones están compuestos por (1) un entrepaño central de romboides concéntricos arreglados verticalmente que son flanqueados a ambos lados por filas de triángulos negros colgantes (el tipo B de Rowe [1994]); (2) un entrepaño central de dos bandas verticales compuestas de una doble equis (en forma de reloj de arena) y barras secuenciales alternadas y flanqueadas, ya sea por el motivo de árbol (el "helecho" en la terminología antigua) o por filas de triángulos pendientes (el tipo A según Rowe) y (3) un entrepaño central compuesto por una banda horizontal de romboides ( variante del tipo B de Rowe) (Figura 7).

El último patrón de diseño descrito es en general el más común, presentando una distribución relativamente uniforme en el centro y en las provincias. A su vez, está representado en cerca del $25 \%$ de los aríbalos decorados en ambas zonas. Sin embargo, no se puede decir lo mismo para los otros dos patrones de diseño, en los cuales se destaca un entrepaño frontal dividido en un campo tripartito. Ambos patrones comprenden $45 \%$ de todos los aríbalos decorados del centro del Tawantinsuyo, pero solamente el 26\% de los aríbalos decorados de las provincias. Esta diferencia en la distribución de los patrones de diseño es significativa a un nivel de confianza de 0,99 . La distribución no al azar comentada sugiere que el significado simbólico de estos patrones de diseño probablemente no tuvo el mismo sentido para la gente de las provincias que para los residentes del centro imperial, pudiera ser que al estado le interesara comunicar mensajes diferentes al pueblo de las regiones interiores.

En base al contexto de hallazgos arqueológicos, a la morfología de la vasija y a su función de probable recipiente para la chicha, sugiero que los patrones de diseño sumamente estandarizadas encontrados en los famosos aríbalos incaicos representan un tipo de iconografía genealógica. Varios eruditos han notado la importancia de la estructura tripartita en el pensamiento andino, los sistemas de parentesco y la organización política (Isbell 1978; Silverblatt 1987; Zuidema 1977). Su 


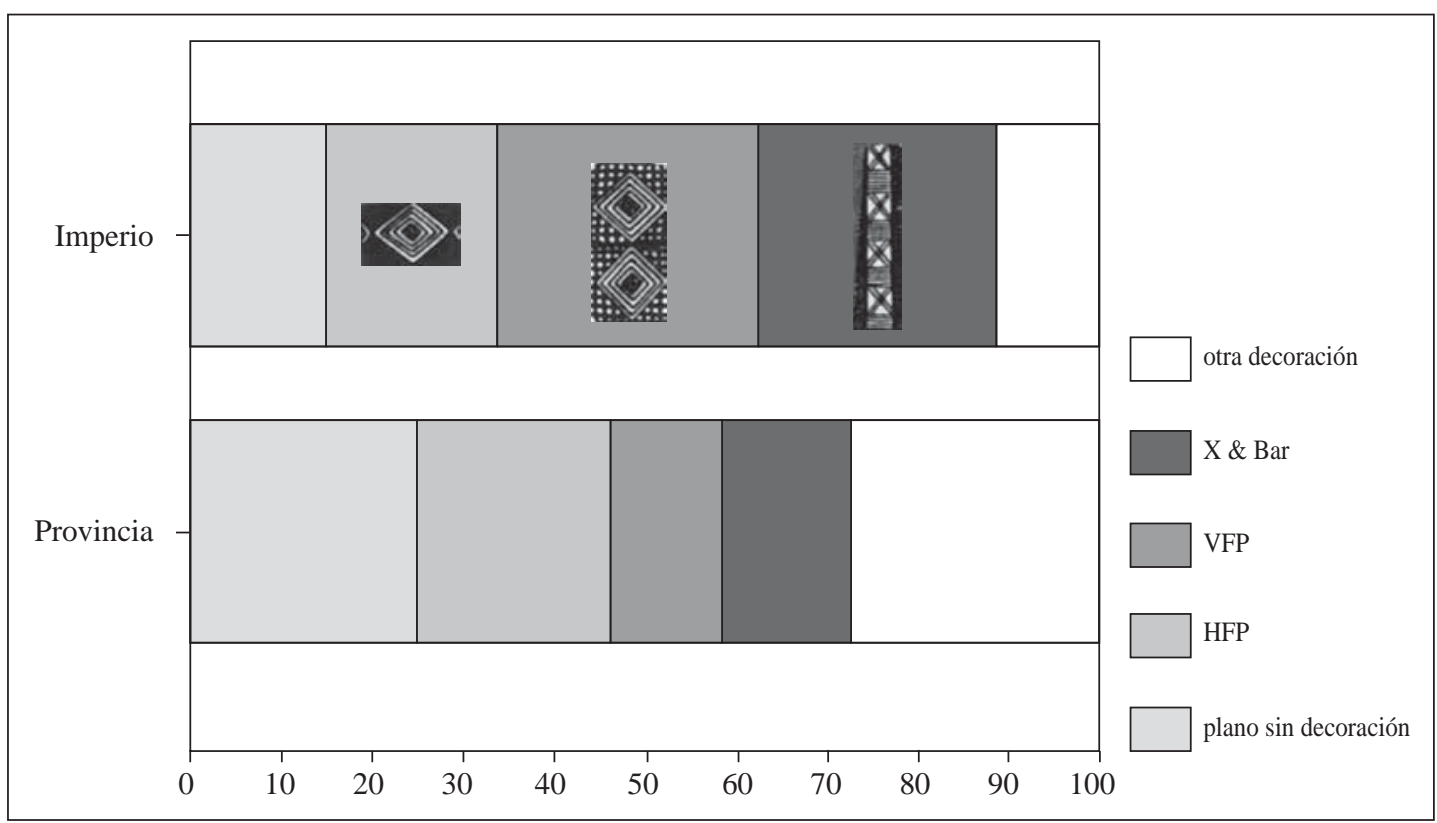

Figura 6. Comparación de la distribución de los patrones de diseño encontrados en los aríbalos del centro con los de las provincias. Distribution of design patterns found on aríbalos from the heartland versus the provinces.

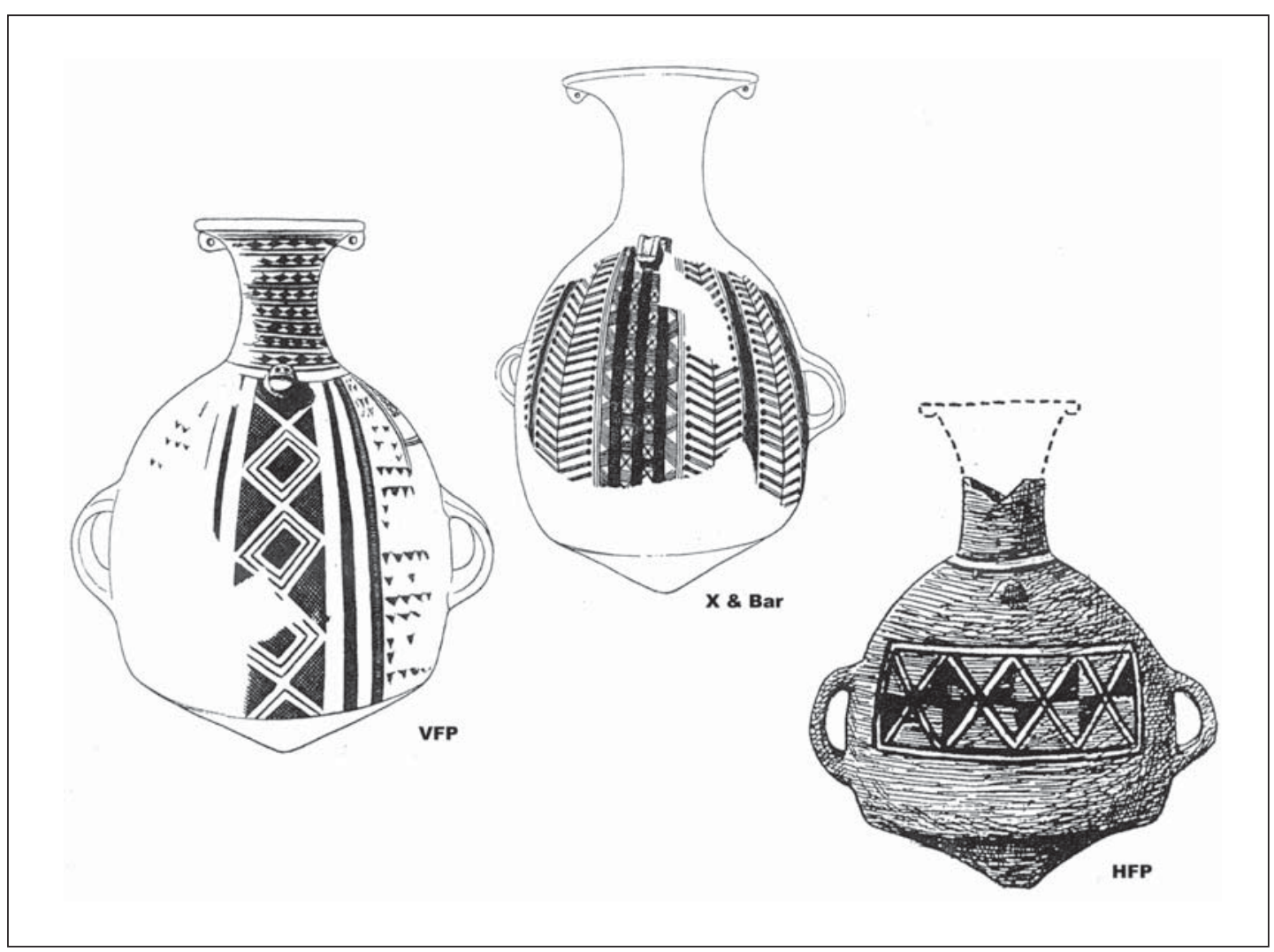

Figura 7. Ejemplos de los tres tipos de patrones de diseño más comúnmente asociados con los aríbalos. Examples of the three main types of design patterns associated with the Inka aríbalo. 
significado se ilustra gráficamente en el dibujo de Pachacuti Yamqui en el lugar del nacimiento del Inka, representado como tres ventanas o cuevas, de las cuales la central está flanqueada por dos árboles a los que Pachacuti yamqui se refiere como la madre y el padre del Inka (Figura 8). Sugiero que la iconografía Inka vista en el conjunto de la cerámica estatal, hace simbólicamente referencia a la importancia de esta estructura tripartita en el pensamiento andino.

Los estudios comparativos de sociedades tradicionales ofrecen una fuerte evidencia en cuanto a que los patrones y simbolismo genealógicos se basan en la premisa de que el individuo se compone de dos mitades, respectivamente derivadas de las mitades correspondientes a cada padre (Schuster y Carpenter 1996:154). Motivos singulares extraídos de patrones con significado genealógico frecuentemente acentúan esta separación entre mitades. Sugiero que puede apreciarse este patrón en la separación por la mitad del motivo Inka común del árbol que ramifican y en la división tripartita general del campo de diseño (Figura 9). Otro elemento común del simbolismo genealógico es una banda vertical delineada por un zigzag, que ha sido interpretada como la columna espinal que une y divide simultáneamente el cuerpo social en moiedades o mitades exógamas (Schuster y Carpenter 1996:60) (Figura 10). Los relojes de arena y los diamantes o romboides son motivos clásicos del sistema biaxial que, se entiende, representan los principios de descendencia dentro de este marco. Las cadenas opuestas en zigzag horizontales o al lado de la columna central han sido interpretadas como la simbolización de los linajes o de las relaciones dentro de una sola generación (Figura 11).

Sugiero que estos dos patrones de diseño comunes en los aríbalos pueden ser interpretados como una forma de iconografía genealógica, con

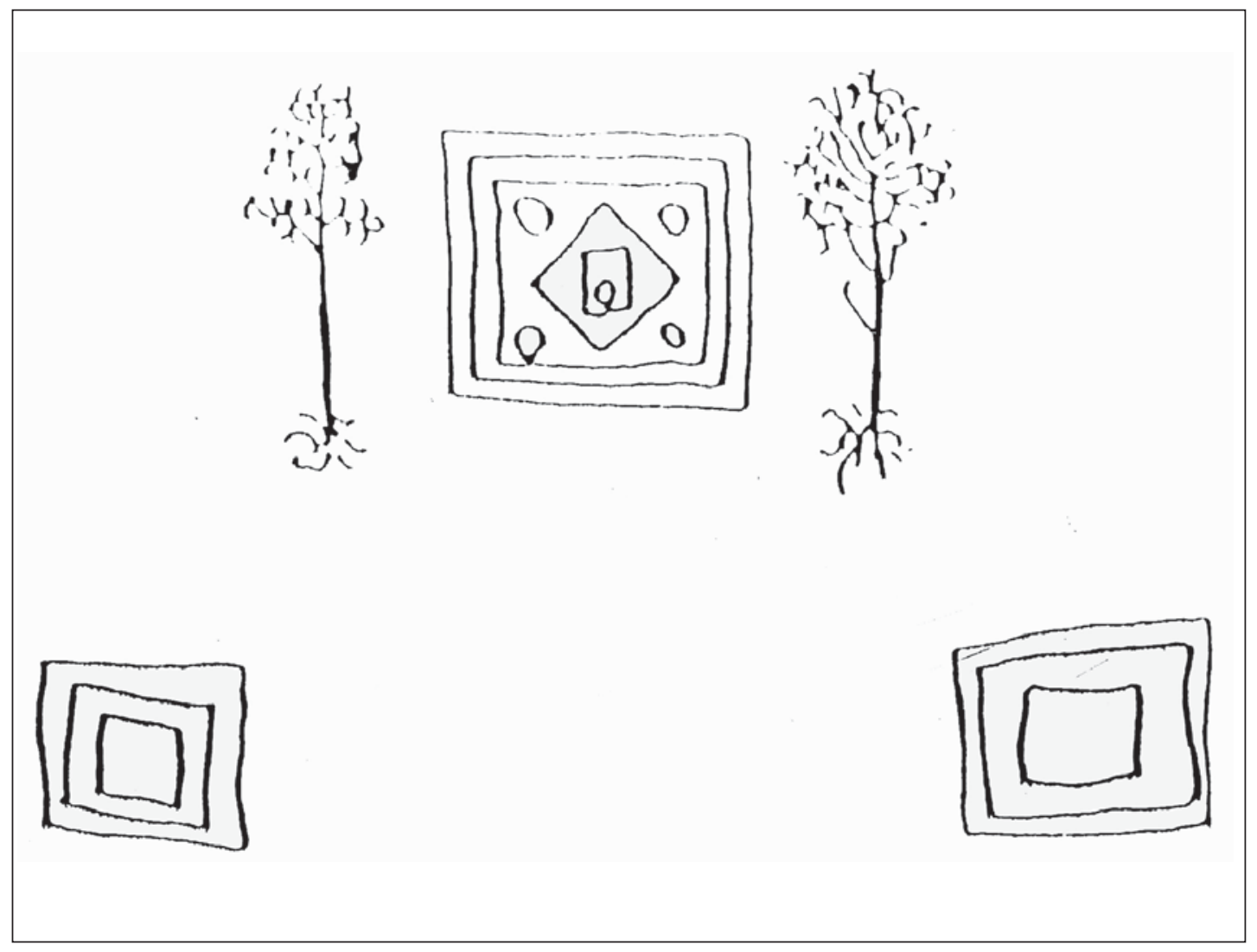

Figura 8. Dibujo de Pachacuti Yamqui (1927 [1613]:144) simbolizando el lugar de nacimiento de los Inka. Pachacuti Yamqui's (1927 [1613]:144) schematic representation of the birthplace of the Inka. 


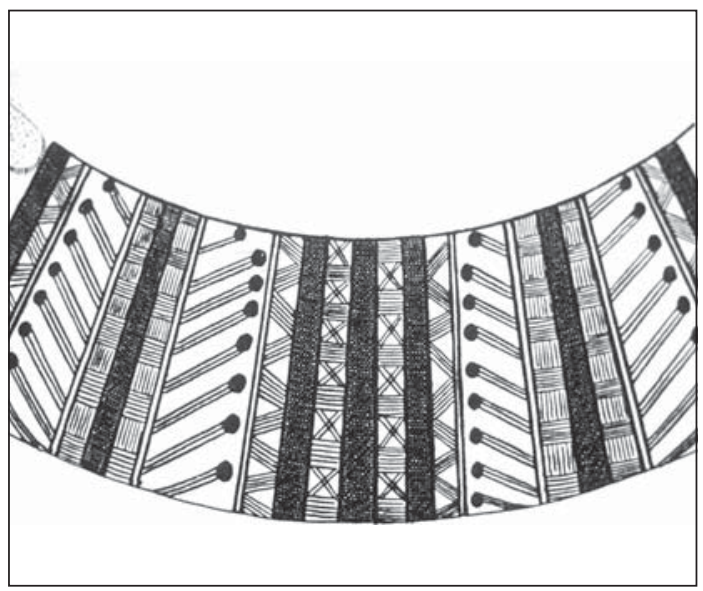

Figura 9. Dibujo de un entrepaño frontal representando la estructura tripartita de una vasija Inka con el motivo común del árbol que ramifica dividiendo las mitades.

Drawing representing the tripartite structure of the front panel of an Inka vessel with the common tree motif here divided down the middle flanking the center unit.

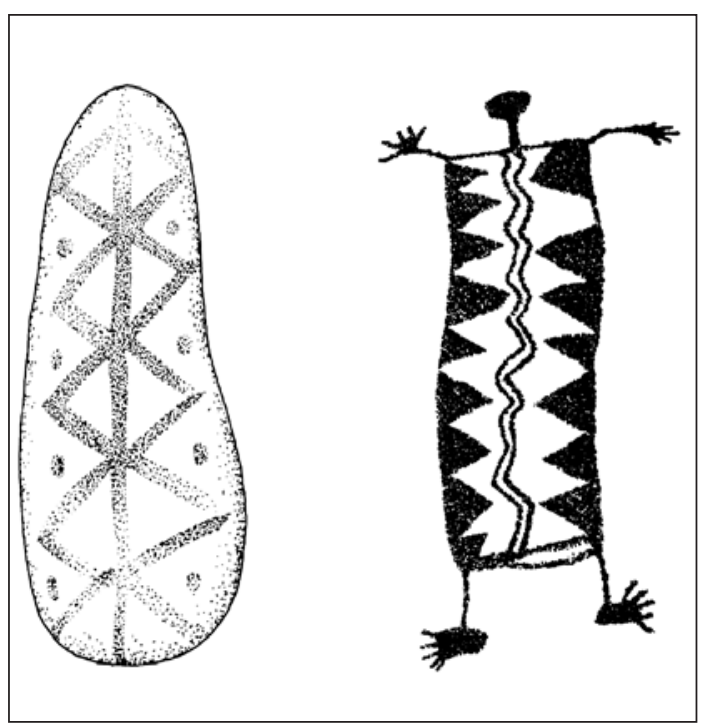

Figura 10. Dibujo de elementos comunes del simbolismo genealógico representando la columna espinal (siguiendo a Schuster y Carpenter 1996:261).

Common genealogical symbols representing the spinal column (after Schuster and Carpenter 1996:261).

los motivos de romboides concéntricos verticales y/o la figura del reloj de arena en el entrepaño central enfatizando la descendencia y las filas horizontales de triángulos pendientes (o zigzag) y/o los árboles que ramifican, haciendo referencia a rela-

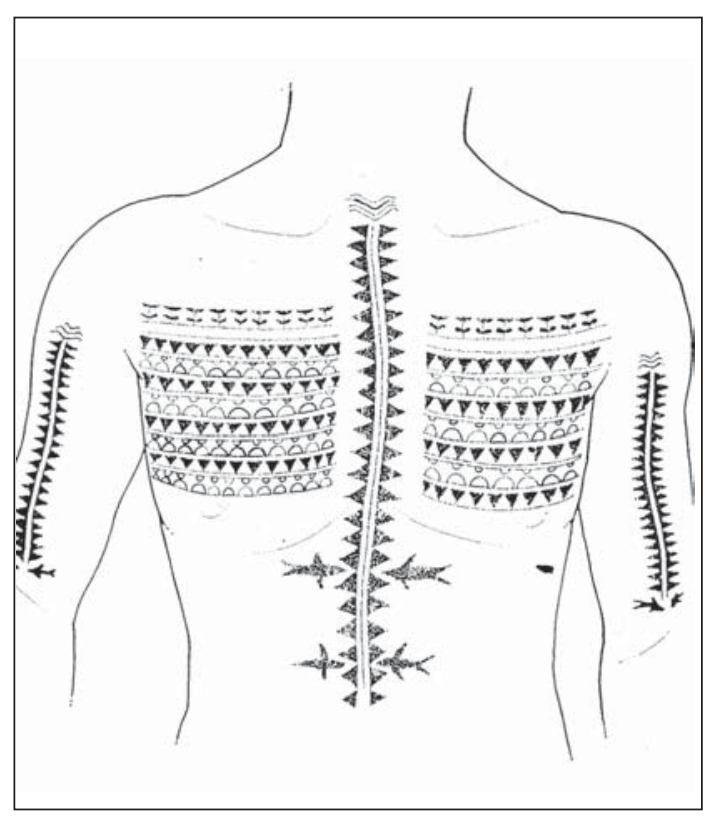

Figura 11. Patrón de diseño genealógico enmarcando el cuerpo social (siguiendo a Schuster y Carpenter 1996:154).

A genealogical design pattern marking the social body (after Schuster and Carpenter 1996:154).

ciones de una sola generación. El hecho de que estos dos patrones de diseño sean apreciablemente menos comunes en las provincias, quizás se deba a que el significado simbólico de esta iconografía no haya sido tan rápidamente entendido por las poblaciones provinciales como lo fue entre la élite incaica del centro imperial.

\section{Conclusiones}

A manera de conclusión, propongo que los patrones identificados y las observaciones hechas de las colecciones de materiales incaicos albergados en museos, en combinación con los datos arqueológicos, tienen mucho que contribuir a nuestra comprensión de las prácticas materiales simbólicas y de las estrategias imperiales del estado Inka. El análisis actual sistemático y comparativo de la iconografía y alfarería incaica debe continuar ampliando nuestra comprensión sobre el papel de la cultura material en la construcción del Tawantinsuyu, la manera en que se diseminó la ideología imperial y las estrategias diferenciales aplicadas por el estado en contextos y regiones diferentes. 


\section{Referencias Citadas}

Bray, T.L.

2003a Inca pottery as culinary equipment: Food, feasting, and gender in imperial state design. Latin American Antiquity 14:1-22.

2003b To dine splendidly: Imperial pottery, commensal politics and the Inca state. En The Archaeology and Politics of Food and Feasting in Early States and Empires, editado por T.L. Bray, pp. 142-163. Kluwer Academic/Plenum Press, New York.

Isbell, B.J.

1978 To Defend Ourselves. University of Texas Press, Austin.

Jones, J.

1964 Art of Empire: Inca of Peru. Museum of Primitive Art, New York.

Meyers, A.

1975 Algunos problemas en la clasificación del estilo incai-

co. Pumapunku 8:7-25

Morris, C. y D. Thompson

1985 Huánuco Pampa. Thames and Hudson, London.

Moseley, M.

1992 The Inca and Their Ancestors. Thames and Hudson, London.

Murra, J.

1980 Economic Organization of the Inka State. JAI Press, Greenwich, Conn.
Pachacuti Yamqui, J.

1927 [1613] Relación de Antiguedades deste Reyno del Pirú, editado por H.H. Urteaga. Colección de Libros y Documentos Referentes a la Historia del Peru, 2nd series, Vol. 9. Imprenta y Libreria Sanmarti, Lima.

Rowe, J.

1944 An introduction to the archaeology of Cuzco. Papers of the Peabody Museum of American Archaeology and Ethnology, Harvard University 27(2).

1982 Inka policies and institutions relating to the cultural unification of the empire. En The Inca and Aztec States, 1400-1800, editado por G. Collier, R. Rosaldo, y J. Wirth, pp. 93-118. Academic Press, New York.

Schuster, C. y E. Carpenter

1996 Patterns that Connect: Social Symbolism in Ancient and Tribal Art. Harry N. Abrams, Inc., New York.

Silverblatt, I.

1987 Moon, Sun, and Witches. Princeton University Press, Princeton.

Zuidema, R.T.

1977 The Inca kingship system: A new theoretical view. En Andean Kingship and Marriage, editado por R. Bolton and E. Mayer, pp. 240-281. American Anthropological Association, Special Publication No. 7, Washington, D.C. 